\title{
Discussion and Analysis on Cui Daorong's Poems in the Late Tang Dynasty
}

\author{
Qian $\mathrm{Hu}$ \\ Department of Chinese \\ Xiamen University \\ Xiamen, Fujian, China 361005
}

\begin{abstract}
Cui Daorong (? - 907), born in Jingzhou in Tang Dynasty, was an influential member of Cui' family in Boling. He gave himself an alternative name "Dong-Ou Sanren" (a leisure man fond of wining). He was friendly with Si-Kong Tu, Fang Gan, and Huang Tao etc. He excelled at composing poems of four lines. His poems had been highly evaluated by Xin Wenfang in Yuan Dynasty, most of them, however, are non-existent today. There are only 79 poems and 2 incomplete works of him collected in Complete Collection of Tang Poetry. Therefore, he has been long before neglected by academia. This paper intends to analyze Cui's special perspective, inclination to be a hermit, doomsday mood, pitying- peasant thought from his poems for history, for social intercourse, for nostalgia and for farming work etc, and then to get knowledge of his artistic achievement in terms of the poems. In addition, through Cui's poems, we could appreciate the secret mind and in-depth mood of poets in the late Tang Dynasty, expecting to help us study on poetic circles in the late Tang Dynasty and the Five Dynasties.
\end{abstract} poems

Keywords-poets in the late Tang Dynasty; Cui Daorong;

\section{Catalogs and Thought Connotation OF CuI's POEMS}

Cui Daorong, unknown birth date, died in Tianyou regin the fourth year (AD907). As an influential member of Cui' family in Boling He was born in Jinzhou and gave himself an alternative name "Dong-Ou Sanren". He was friendly with Si-Kong Tu, Fang Gan, and Huang Tao etc. He excelled at composing poems of four lines. His poems had been highly evaluated by Xin Wenfang in Yuan Dynasty. Xin Wenfang praised that "Cui was versed in composing poems of four lines with excellent words and connotation ... it's impressive that there were such quality works in the late Tang Dynasty. Even if the predecessor could have had been alive, his works might not as good as Cui's. Therefore, Cui was above the common herd compared with his counterparts. It was recognized that he was graceful and elegant. Unfortunately, the detailed information of his origin could not be summarized".[15] Most of his works, however, are non-existent today. There are only 79 poems and 2 incomplete works of him collected in Complete Collection of Tang Poetry. Therefore, he has been long before neglected by academia. According to the subject, his works can be divided into poems for history, for social intercourse, for nostalgia and for farming work and etc. From these poems, we can sense Cui's doldrums and anguish, pessimistic attitude, inclination to be a hermit, pitying- peasant thought and etc in the late Tang Dynasty, and then to get knowledge of his artistic achievement.

\section{A. Special Perspective of Poems For History}

Poems for history Cui Daorong composed include Tong Que Ji Er Shou, Xishi Tan, Xishi, Han Palace Ci, Ban Jieyu, 2 poems of Complaints in the High Gate, Luan Jia Dong Hui, Mawei, Jie Gu, Guo Longzhong, King Huai of Chu and etc. These poems either review the history and express new ideas, or narrate anecdotes of the past in alluding to the present, "indirect and satirical", or show identity of object and self, reflection and mourning for himself, or express his hopes and ambitions, depicting his unique historical view. For instance, in the well-known history of Xishi, abandoning the traditional "dangerous beauty" theory, he believes that the death of Wu State results from the avarice of Zai Pi. Whether this conclusion is in accordance with historical fact, it is well worth for us learning from Cui's thought-provoking and routine-breaking view. In addition, in poem of Xishi Tan he combines "washing clothes besides rapid spring rivulet" with Xishi's "unfair complaints (uneven sound)", which is the perfect match between discussion and expressing emotions. Another instance, in Guo Longzhong when he reviews on historical vicissitudes, he reminds us of attaching importance to Xu Shu's efforts to establish and develop the Kingdom of Shu. We should not neglect him after he comes into the Kingdom of Wei. This embodies Cui's advanced contemporary view of history. And this innovative and thought-provoking point of view is well depicted in Complaints in the High Gate. The story of "keeping a charming young wife in a plush house" is widely read. Men of letters often regard Chen Ajiao and Songs in the High Gate as boudoir repining and show sympathy, or criticize the emperor for being a heartless lover. However, Cui, speaking in the empress Chen's (Chen Ajiao) voice, criticized the writer of the Songs in the High Gate Si-Ma Xiangru was not constant in love. By this way, the "victim" under the cruel system of feudal royal court becomes "criticizer", forming a kind of extremely large artistic tension.

Secondly, facing the separatism regimes and eunuch monopolizing power, society beset with domestic troubles and foreign invasion and social unrest in the late Tang 
Dynasty, Cui had the innate sense of mission to narrate anecdotes of the past in alluding to the present in his poems. It was often applied in poems for history. For instance, the Tong Que Ji Er Shou memorizing Cao Cao's reign is in memory of the past flourishing Tang Dynasty and with a deep sigh facing realistic declines. Songs for General Li's Biography selects roughness-riddled Li Guang as protagonist to express his being unlucky to be born at such a time and being squeezed out several times. Compared with the late Tang Dynasty, the court in this period was also in the bad situation. Undoubtedly, his poems conclude his deep concerns about the on-the-thorn governors. He would like to take this opportunity to tell the governors they should make good use of talents but not repeat the tragedy. The King Huai in King Huai of Chu heard and believed slanders and then let him dead and his state perish. The poem paid attention to the governor's incompetence and summarized the necessity of Chu State's death from fortuity with close association between narration, discussion and lyric. Luan Jia Dong Hui, Mawei, and Jie Gu also took the An Lushan Rebellion as an example to express the governors were wallowing in luxury and pleasure. All of the poems mentioned expressed poems for history in the late Tang Dynasty were "deep complaining" and "indirect satirical", with feature of sarcasm and criticism closely associated with current politics, embodying ancient men of letters were rationally mulling over and reflecting the reality.

Thirdly, in the late Tang Dynasty, the country was in decline with social unrest. In this severe catastrophe-ridden ear, men of letters had the same destiny that they had no opportunities to use their talents and their double-edged treasured swords were dusted. Personal idea and ambition the flourishing Tang Dynasty expressed were gradually replaced by sorrowful and mourning personal destiny. Therefore, in this period there emerged many historical features in the poems, such as Bi Gan, Wu Zixu, Xi Shi, Xiang Yu, Han Xin, Qu Yuan, Su Wu, Jia Yi and Imperial concubine Lady Yang Guifei. All of them were the features poets meditated on the past. In Cui's Han Gong Ci, Wang Zhaojun went far away from her hometown and on the way to minority's region for she was not favored by the emperor. Ban Jieyu in Ban Jieyu was lonely until death since the emperor took a false charge for truth. Li Guang in Songs for General Li's Biography had no choice to commit a suicide for he had not been appointed an important position... Cui was angry and was full of sympathy with the features in his works. In fact, it was a kind of depressed and discontented mood since he lived in an unrest society with vicissitudes of life. When we look back to Cui's life experience, he was appointed to be Yongjia County leader, and then entered into royal court to be right Buque (directly admonishing the emperor). But finally the country was invaded so he went into Fujian area for escaping from war. He was once an ambitious man of letters, but he was just anguished for he had bad luck then he indulged himself into suspicion and reflection against Confucianism. Thus, tragic characters that were "born under an unlucky star" just represented the fact that Cui had no opportunity to use his talents and he can help himself but be indignant. It was just the reason why poems for history in the late Tang Dynasty showed the unique deep sorrowful aesthetics.

Lastly, appreciating Cui's poems, readers could sense the hopes the poet pinned on. For instance, the "Mawei Incident" and love story of Emperor Li Longji and Yang Guifei were repeatedly mentioned in Luan Jia Dong Hui, Mawei, and Jie $G u$, which was like visiting and meditating the past flourishing Tang Dynasty. Maweipo, as the iconic venue, witnessed the Tang Dynasty changing from flourish to decadence. This image often cited by poets in the late Tang Dynasty, reflecting the poets living in a situation from bad to worse felt the flourishing, vital, free and concrete Tang Dynasty had past away, replaced by decayed, decadent, warring and depressed condition. Therefore, they could just memorized the "Peace and Prosperity of the Kaiyuan Years (713-741), hey day of Li Longii's entire reign" by their works.

It is while worth mentioning that although poems for history had had been since prior period, the poems ascended to a peak in the late Tang Dynasty. According to Mr. Lin Geng's statistics, there are 1014 poems for history in the late Tang Dynasty, accounting for $6.9 \%$ in the total. It is perhaps associated with the factor of current situation and the poets' memory for past prosperity. Cui's poems for history undoubtedly reflect the common characteristic, putting forward novel ideas and remolding old stories to show he is different from the previous run. It is also evident in the poems for history by famous poets $\mathrm{Li}$ Shangyin and $\mathrm{Du} \mathrm{Fu}$ in the late Tang Dynasty.

\section{B. Inclination of Reclusion in Poems for Landscape and for Social Intercourse}

Cui Daorong had traveled Shaanxi, Hubei, Henan, Jiangxi, Zhejiang and Fujian etc, making friends with SiKong Tu, Fang Gan, Huang Tao and other Buddhist monks, which provides him many quality materials to depict landscapes and friendships in poems. The existent poems for landscape Mei flower, Yue Xi, Jiang Xi, Ni Yue Fu Zi Ye Si Shi Ge Si Shou, Chun Wan, Gu Shu, Chun Ti Er Shou, Mei, Xi Shang Yu Yu Er Shou, Xi Ye, Cun Shu, Qiu Ji, Yang Liu $\mathrm{Zhi} \mathrm{Ci}$ etc, and poems for friendships Fang Seng Bu Yu, Jiang Shang Feng Gu Ren, Tian Tai Chen Yi Ren, Xue Dou Chan Shi, Shan Jv Wo Ji Guang Li Da Shi Jian Fang, Jiao Jv You Ren Xiang Fang, Jing Hu Xue Ji Yi Fang Gan, Xie Zhu Chang Shi Ji Kuang Shu Cha Yan Zhi Er Shou, Dui Zao Mei Ji You Ren Er Shou etc express poems in the late Tang Dynasty had no choice but held an inclination to be recluse.

Specifically, Mei Hua and Mei selected Chinese mei flower, the most representative items for living in seclusion and elegance to indicate their indifference and hofty sentiment. "Unique charm is in the fragrance the elegance makes you forget the coldness" and "I felt lonely and lovesick in the bleak moonlight night, waiting for a master musician to relief my sorrow" in the two poems clearly describe the Chinese mei flower, which transcends worldliness and attains holiness with poetic charming. The vivid words like one combination of poems and paintings. Therefore, the works have been highly praised by many 
poets in all ages. Yue $X i$ and Jiang $X i$ depict night scenes when leading an idle and quiet life. The moonshine is bright and clear with tranquil environment, as if it brings readers into an excellent resort to enjoy the scene. "A child suddenly thought there came a guest, hushed into the wooden gate but it was closed." In Xi Jv Ji Shi paints a vivid countryside picture. The language is natural and the depicting technique is simple, full of humorous interest. $\mathrm{Yu} \mathrm{Xin} \mathrm{Ji}$ also directly expresses Cui's infinitely praising highly on Tao Yuanming's poems and his living in seclusion. Xi Shang Yu $Y$ Y Er Shou describes rainstorm in a summer night and a farmer's activity. "I was given a start because the rainstorm had fallen on my head, and immediately I found there was a sunset glow reflecting before the green mountains" shows us the hurrying of rainstorm. Gu Shu praises a thriving old tree, expressing Cui's passionate love for nature. Meanwhile, "do not think the old tree is at the end of life, now it stretches unflagging branches" can also be regarded as a hope and expectation to himself. Other works such as Ni Yue Fu Zi Ye Si Shi Ge Si Shou, Chun Wan, Chun Ti Er Shou, Xi Ye, Cuo $\mathrm{Shu}$, Qiu Ji and Yang Liu Zhi Ci etc describe countryside scenes or narrate rural life, showing the leisure and satisfaction in seclusion. Fresh and elegant beauty is between the lines.

In addition, some Cui's poems for social intercourse with hermits and monks also embody his inclination to live in seclusion, such as Fang Seng Bu Yu depicts Cui's process and experience during visiting a monk. Jiang Shang Feng $G u$ Ren records the old friends reunion and talk about the old days over wine. Tian Tai Chen Yi Ren praises Chen Yiren" believing strong desire is like dust before a vast ocean, I am not afraid of tigers and wolves but human." Does he not want to express his attitude to live a sequestered life? Both Xue Dou Chan Shi and Shan Jv Wo Ji Guang Li Da Shi Jian Fang depict the monk leads a recluse life. Jiao Jv You Ren Xiang Fang and Jing Hu Xue Ji Yi Fang Gan also describe Cui's life with his friends. Xie Zhu Chang Shi Ji Kuang Shu Cha Shan Zhi Er Shou expresses what he concerns about when grinding an ink stick and tasting the tea charm. Dui Zao Mei Ji You Ren Er Shou depicts Cui's contrast mei with past friends or family. All of them speak of Cui's sentiment beyond mundane affairs. Another work $\mathrm{Yu}$ Yin $\mathrm{Ji}$ describes his life:"each work by Tao Yuanming mentions wine. Every line of poem by Cui Daorong could not be composed without wine glass. I would like to be drunk and agree with myself, to abandon the laureate of poet and become Bacchus", which directly expresses Cui's admiring for Tao Yuanming.

As an ancient man of letters deeply influenced by Confucianism education, why did Cui have this evident inclination to live in seclusion? First, "living in seclusion" was a kind of cultural phenomenon affecting Chinese ancient men of letters far and wide. Since $\mathrm{Xu}$ You and $\mathrm{Chao} \mathrm{Fu}$, the complex of living in seclusion had followed men of letters like a shadow. Living in a precarious society and working in royal court, the men of letters were full of imagination that they could lead a tranquil and peaceful life in countryside detached from reality without any restraint physically and mentally. They highly praised ancient hermits especially referring to Tao Yuanmin. Therefore, there came poems of
Tao's style and Tao-imitating style. In the late Tang Dynasty, Jia Dao, Lu Guimeng, Pi Rixiu, Du Xunhe, Fang Gan, Zheng $\mathrm{Gu}, \mathrm{Cao} \mathrm{Ye}$ and Si-Kong Tu etc a great many poets were influenced by the culture of living in seclusion. We could find many seclusion images in their creations, in which the beauty and leisure of idyllic life were exposed. The above Cui's poems for landscapes also express the limitless pleasure of being far from mundane life and being free and easy. And the $Y u$ Yin $J i$ was more directly expressing Cui's life pursuit of praising freedom and taking delight in poverty and virtue.

Certainly, it is well known that the life of Chinese ancient men of letters always has the whereabouts and their spirit has its entrustment. Even though some men chose to live in seclusion for this or that reason, some of them still had great personal ambition in the bottom of heart. Even the "Zhong Nan short cut (most convenient method to gain fame and fortune)" also contains the men's political ambition. Thus, the previous "seclusion" of poets in the Tang Dynasty is well worth deep thinking of readers. In the late Tang Dynasty, facing the political corruption, increasing crisis, frequent wars and disadvantages of imperial examinations, the expectations and ambitions of the men of letters could not be realized. Such as Huang Tao said: "In Xian Tong reign (860874) and Qian Fu reign (874-879), rich people and noble class stopped the social ladder, and a plain civilian was often destined to fail." ( Pushan Mountain Lingyan Temple Epitaph) [20] In this period, the high spirit and vigor in flourishing Tang Dynasty died away without any trace. In royal court, each party united with those of the same views but alienate those with different ones, courtiers persecuted loyal and talent ministers who made a precarious living. For avoiding calamity, going far away from the precarious political situation, the men of letters had to choose seclusion. Tang Talents Bibliography read "from flourishing Tang Dynasty to a declined period, governing days were less and social unrest was more. Even the poor could not live a peaceful life. In that time, people living by fishing and birding dared not working around mountains but at sea. Then some people with virtue had to be in seclusion. Apart from the emperor, occasionally some people chose to be hermits. People who were not migrated should be cautious about their activities and speeches in order to avoid danger. Whether you were a pauper or a prince, you just wanted to retreat from the chaos."[21] But they had no choice and just were angry. They were laden with grief written in the lines "Since we could not find Yao and Shun(ancient sages) to be appointed, we could pin our hopes on mist and haze(a competent man has no opportunity to show histalents)"(Lu Guimeng's Feng He Xi Mei Chu Xia You Leng Jia Jing She Ci Yun). We could know a little about the grief from many Cui's poems for friendship. Such as Fang Seng Bu Yu:"I felt so lonely that I visited a monk, but unfortunately his door locked in the forest." Jiang Shang Feng Gu Ren: "I was drunk in a riverside country, tears shedding down face becoming laughter." Jiao Jv You Ren Xiang Fang: "the wooden door was closed reflecting the ancient city's autumn silhouette, in the back of the city there was a winding path tracing to a creek." Jing Hu Xue Ji Yi Fang Gan said: "I happened to read the poem over half-drunk misery, which 
could counteract the noise by apes and birds." From these works we could deduce that compared with previous Chinese ancient seclusion culture, the seclusion of men of letters in the late Tang Dynasty added more helpless mood to escape disaster and felt more grieved for their life experience. To choose seclusion was just a temporary mental comfort which was gloomy of disposition and sullen of temper and a spiritual homeland without other any choice as they lived in an unrest society with their country subjugated and family wrecked, they had bad luck of their political career. Frankly, the seclusion sentiment of men of letters in this period indicated special characteristics of the times.

Thirdly, the sentiment seclusion was also associated with poets' friend-making condition and life experience. Cui had traveled Shaanxi, Hubei, Henan, Jiangxi, Zhejiang and Fujian etc. He had been around and most of his friends were monks, hermits and recluses. Therefore, he had passionate love for the tranquil life of appreciating the moon, having some tea, playing some music and playing chess. His poem Fang Seng Bu Yu:"I felt so lonely that I visited a monk, but unfortunately his door locked in the forest." Jiao Jv You Ren Xiang Fang: "the wooden door was closed reflecting the ancient city's autumn silhouette, in the back of the city there was a winding path tracing to a creek." Jing Hu Xue Ji Yi Fang Gan: "I happened to read the poem over half-drunk misery, which could counteract the noise by apes and birds." The works reflected his social intercourse with his friends and they were of like mind. Poets failing to realize their political ambition would rather linger about poems and books, mountains and rivers with hermits and took this kind of life as pleasure. Meanwhile, the men of letters who lead the sequestered life often took reading poems as pleasure to ease melancholy and to improve their literary talents. For instance, in the late Tang Dynasty, Liu Deren, Fang Gan and Zhou Pu often responded with poems. Since they had similar life experience and destiny, the like attracted like. They comforted each other and responded with poems. They even developed a school of Mountain and Forest Seclusion Poem. Cui's Jing Hu Xue Ji Yi Fang Gan just reflected this style in this period. In the same time, the trend also reflected the obvious difference between feudal men of letters in this period and heroic attitude of men of letters in flourishing Tang Dynasty.

Lastly, poets in this period were influenced by Buddhism. In the late Tang Dynasty, most of the imperators advocated Buddhism and they wanted to take advantage of the religious power to manipulate populace. In this period, there emerged many Taoist temples and monk poets, which provided a social condition for men of letters to get knowledge of Buddhism and Taoism. In addition, the mentality resulting from the fact that men of letters had no choice but selected seclusion found its home in the religious doctrines. They freed themselves mentally. Thus, religious theory in this period exerted influence on men of letters deeply. They admired the elegant and refined life the monks and Taoists lead. Then they made friends with each other and responded with poems. Therefore, there were many famous monk poets such as Wu Ke, Guan Xiu, Qi Ji, Xu Zhong, Shang Yan and Qi Bai etc in this period. The monk poets also created many poems concerning Buddhism, which embodied the deep influence exerted by Buddhism. And in terms of Taoism's influence, poem collects of Li Shang Yin used many Taoism lingoes and the Immortal images to make his poems have obscure and hard-to-understand aesthetics. And Cui's $Y u T i$ : "if you go to sea and you will meet the Immortal, he could not have bones and boat. In mundane world there is pivot stone, which could levy your undeserved reputation on to sky." and etc. The work expressed that the poet believed the legend of Immortal without a shadow of doubt, which functioned greatly to help Cui develop the inclination of living in seclusion.

\section{Doomsday Mood Expressed in Poems for Friends, Trips and Nostalgia}

As Wang Guowei said: "each time enjoys its literature with time's characteristic". Sao in the Chu State period, fu in the Han Dynasty, jiaoyu in the Six Weijin Dynasties, poem in the Tang Dynasty, ci in the Song Dynasty and qu in the Yuan Dynasty, each of them belongs to one era's literature." In the late Tang Dynasty, the country was in decline and the political situation was in chaos. Men of letters could not realize their political ambition. Their mental condition was at the verge of breaking down of Confucianism and in contradiction. When this social condition was reflected into poems, it showed us doomsday's and distress's mood. Works created by poets in the late Tang Dynasty showed a bleak sense of current situation and miserable scenes. In addition, in this period the poems pursued a kind of aesthetic style: "gust generated flood and woods were destroyed. Miserable is to die but not rest in peace. Time flew, taking away the rich and poor. The normal life ceases to be even you are a talent. When a strong warrior holds his double-edged sword, he just sighs with grief. Leaves fall and leakage of rain generates moss." (Si-Kong Tu's Shi Pin) The bleak scene was described in the above lines. Thus, they often used sunset, incomplete sun, isolated mountain, immigrated birds, white bones and wild braves as images to track back history or to ascend a height to memorize the past, or seeing off immigrated birds representing miss their hometowns or bewailing the aging and sickness, lamenting life...

Cui Daorong, certainly, was not exceptional. In the poem for friends Ji Ren Er Shou: "Spring is almost over when I miss my friends. The wine cup is empty but I still cannot make my sorrow die away. The flowers are full of hatred when falling, but once on the ground they are silent." $\mathrm{Ji} \mathrm{Li}$ Zuo Si: "I believe all men are brothers, but we part until the end of life." This poem expressed the poet was missing his friends and felt sad about spring and autumn. Poems for trips such as Lv Xing, Yue Xi You Huai, Ye Bo Jiu Jiang, Han Shi Ye, Han Shi Ke Zhong You Huai, Xia Lu and Gui Yan, all of them expressed the poet was missing his hometown and it was tough to go through the journey when in official travel. Poems for nostalgia expressed clearly the doomsday mood. Bing Qi Er Shou described the ache of Cui's valetudinarianism, missing family and expecting reunion. Yue $X i$ depicted that Cui was ascending height in the moonlight. There is no special image of the poem but if you peruse it you could find its meaning profound. In this poem, 
the moon was shown "according to man's intention", but the man was idling away. When he ascended the Zhu Lou, he could not see the daybreak, which means the poet could not see any hope and future and he was lonely and empty with hesitation in the dark chaos society. Chun Gui Er Shou depicted in a cold and quiet raining night a household wife was missing her husband on service in Liaoxi. The image of cold dish, bright moon, raining night and falling flowers created a painful and bleak atmosphere for the poem, feeling and setting naturally blended, complement each other. Meanwhile, the household wife who was missing her husband indicated the poet was reflecting and detesting war. The poet here took the household wife to sing memory, containing profound meaning. Jin Hua: "Jin hua flowers can not live until sunset. Everyday you could see the new flowers. Eastwards wind blows the peach and plum trees. You just see the sprouts until spring the next years." Qiu Xi: "it is pity that I have not traveled until 30 . When I search the mountain along the river, the autumn is approaching. There are many memories in my mind over raining dropping sound. All of them come into my heart continuously. "Jiu Xing: "awaking from a drunken sleep i stoke the wooden cinder. How many bleak scenes I feel in these ashes? I drink myself again over the stove. When I open the window, snow and wind beat it in the deep night." All of the works expressed the poet was feeling the time ticking away and no achievement in career, his concerning about his country with sorrow. He wanted to voice the unlimited bleakness. When one could not fulfill his achievement in career with heart sorrowful, it was a best opportunity to pour out his heart to one or two bosom friends. All of the dissatisfaction and depression could be spoken out while drinking. The same miserable destiny indicated many disconsolate experience and melancholy. Then the poet composed a line in Jiang Shang Feng Gu Ren:" I was drunk in a riverside country, tears shedding down face becoming laughter." And Jiang Ou depicted the white birds were reluctant to flay away since they had "heart for fish" but not lingered on over the rivers. Here the birds had human sense. Concerning the poet's life experience, he had had been traveled around many places and later on he lived in seclusion in Yongjia, resulting from the chaos of current politics and moral degradation society. So he suffered a lot from difficulties and he knew the fickleness of the world and even until the end of life he still dared not state his views frankly. And he just could use the plain words to express what he felt through poems for chanting objects. It was another kind of pity. Du Du Zi Wei Ji expressed he admired $\mathrm{Du} \mathrm{Fu}$ could compose poems with power of "gust and thunder". Cui said"how much efforts I make in my life? I would rather live in a peaceful life and idle away." From the appearance, he had pity for Du Fu's "efforts in vain". In fact, he satirized he had no opportunity to attain his ambition and failed to be successful. Even if he had Du Fu's talent to admonish and mock the emperor and society, he just racked his brains in vain. Thus the helplessness was shown between the lines. And Cui's poems for history mentioned the image of Mai Wei many times, showing he was memorizing the flourishing Tang Dynasty. The inclination of seclusion in poems for chanting objects altered from the rebellious sentiment in the beginning to rational peace in the end after experiencing vicissitudes of life. All of them mentioned expressed Cui was using his sentiment and feeling, rough experience to harden himself and expressing "the setting sun is infinite good, just near evening" in the late Tang Dynasty. The bleak scene and the peak of poetic perfection were shown us. This kind of doomsday mood added more sadness and melancholy in his poems.

\section{Pitying Peasant Thought in Poems for Farming}

In addition, Cui had some poems for farming, expressing his sentiment for pitying peasants. Such as $M u$ Shu: “a shepherd boy held a straw rain hat, with his vitality and proud. On cattle's back he blew the short flute when grazing. He took a rest alongside the river and filed when the cattle was cultivating land". The line drawing simply composed a vivid and natural countryside landscape picture. The shepherd, straw rain hat, old cattle, short flute and field alongside river were harmoniously combined with together, shaping a clear and fresh style. Chun Shu: "croaking is near the village, reminding us of the busy farm work awaiting. The neighboring women go back home from field after sending food, they ignore the beautiful flowers on road sides." This poem described what the author saw and felt in the farmland, showing clear and natural sense. Jiang Cun: "When the sunset is approaching, some sails are going down, as if the riverside country knew it. I look at the moonlight on the sand bank alone, hearing the snoring sound from boats." The poem depicted snoring of fishermen form the fishing boat could be vaguely heard after sunset and lowering the sail.

Apart from the mentioned above, Cui's poems for farming work had other special characteristics. Such as Fishing: "fishing men are not fishing for fame, using the rough cup to wine against the green mountains. Falling down into the reeds after drinking, it is ridiculous to have bad fortunes." These poems seemed to express Cui's fishing experience, but telling his own feeling inclination through each line. Facing numerous and complicated society, the poet would like to use the rough cup to wine and finish his busy life lasting by leading a quiet life in the reeds. It was kind of agreeable life. He did not fish for fame, showing his seclusion interest. And Tian Shang: "sufficient rain makes a good time for plough. I do the tillage in the midnight wearing my straw rain hat. My cattle and I are exhausted, but the daybreak has not yet come. "The farmer in a straw rain hat was working hard in a midnight. The farmer and farm cattle were completely exhausted but the daybreak from eastward has not yet approaching. This scene showed Cui's strong compassion. It is well known that in the late Tang Dynasty the most victims were the poor who suffered the corrupt government, separatism and continual wars. The governors increased exploitation and oppression against the populace for the requirement of warring. This undoubtedly aggravated people's heavy burden. The poet pitied the peasants since his travel and migration experience made him approached lower-class miserable life and the Confucianism virtue in his heart let him care about the civilians. In fact, many poets in this period expressed their deep sympathy for the common people through their poems, such as the poets Yuan Jie, 
Yuan Zhen, Pi Rixiu, Lu Guimeng, Nie yizhong and etc. They achieved the same goal with different means. Thus it could be seen that use realistic method to reveal social contradiction, class difference, distressed life and extreme misery to voice their discontents for people, which became a common theme for the poets to express their feelings.

And such as the Rooster: "I bought a rooster for its crowing, but usually I could not use it. Until in the pitch black and rainstorm morning, the first crow means the black night will soon pass." In this scene, there was a stubborn and intractable rooster. It was unreconciled to be mundane. Even in a pitch black night with rainstorm, it still crowed duly. This associated us with the depressed and black political atmosphere which could make people "ten thousand horses stand mute - lack of vitality". In such case, Cui expressed his dissatisfaction and angry by describing the image of the rooster. In fact, was it not an irony of current situation when he created the image of "crowing rooster"? Facing the decline of national power, people kept silent resentment. How could this weird situation not intrigue the poet's indignation? Thus, Cui's lines were so sharp that they could criticize the handling of state affairs and reveal the social darkness. It could be read that Cui's poems for farming work did not describe clear and beautiful idyllic scene but also use realistic method to reflect contradiction and to uphold justice. It showed his pitying - peasant thought which added humanity glory to the poems in the late Tang Dynasty.

\section{CONCLUSION}

Most of works by the poet Cui Daorong in the late Tang Dynasty have been lost. There are only 79 poems and 2 incomplete works of him collected in Complete Collection of Tang Poetry. Therefore, he has been long before neglected by academia. However, his poems have great high thought value and artistic achievement. His poems for history apply the past to satirize the present, or to reflect and mourn himself, or to express his hopes and ambitions, depicting his unique historical view. Composing poems for scene and social intercourse expresses he had no choice but held an inclination to be recluse in the late Tang Dynasty. Poems for friends, trips and chanting contain doomsday's and distress's mood, embodying the mental contradiction and abjection and weariness of men of letters in the late Tang Dynasty. Poems for farming work use the line drawing method to express his elegant and beautiful poetic style. And the poems indicate Cui's courage of criticizing the handling of state affairs and strong pitying-peasant sentiment. In fact, Cui's poems, to some extents, represent the secret mind and in-depth mood of poets in the late Tang Dynasty. Therefore, studying on Cui's poems, undoubtedly, helps us appreciate great achievements the poetic circles in the late Tang Dynasty and the Five Dynasties.

\section{REFERENCES}

[1] Complete Collection of Tang Poetry [M], Beijing: Zhonghua Book Company, 1960, p8202.

[2] Written by Wu Renchen, The Histories of the Ten States [M], Beijing: Zhonghua Book Company, 1963, p1372.
[3] (Qing Dynasty) Written by Li Diaoyuan, Poems of the Five Dynasties [M], Chengdu: Bashu Publishing House, 1992, p1371.

[4] (Song Dynasty) Written by Chen Zhensun. Catalogic Book Zhizhai Shulu Jieti [M], Shanghai: Shanghai Chinese Classics Publishing House, 1987, p579.

[5] (Qing Dynasty) Written by Dong Gao, etc. Complete Prose Works of the Tang, Volume 826 [Z], Beijing: Zhonghua Book Company, 1983, p 8708 .

[6] (Qing Dynasty) Written by Dong Gao, etc. Complete Prose Works of the Tang, Volume 825 [Z], Beijing: Zhonghua Book Company, 1983, p8697-8698.

[7] (Song Dynasty) Written by Ou Yangxiu, Song Qi. New Book of Tang [M], Beijing: Zhonghua Book Company, 1975, p2776.

[8] Edited by Fu Xuancong, Collation and Annotation of Biography of Gifted Scholars of Tang Dynasty [M], Beijing: Zhonghua Book Company, 1995, p1.

[9] Written by Wu Renchen, the Histories of the Ten States, Beijing: Zhonghua Book Company [M], 1963, P1372.

[10] Ming Dynasty, Chen Minghe. Dongyue Wenyuan [M]. The Continuation Books of Complete Library of Four Branches of Books [Z], Shanghai: Shanghai Chinese Classics Publishing House, 1995, p426.

[11] Qing Dynasty, Zheng Fangkun. Notes on Poets and Poetry of Five Dynasties [M], Series of Index to Complete Library of Four Branches of Books [Z], Jinan: Qilu Publishing House, 1997, p635-636.

[12] Written by Wu Renchen, The Histories of the Ten States [M], Beijing: Zhonghua Book Company, 1963, p1372.

[13] (Qing Dynasty) Written by Dong Gao, etc. Complete Prose Works of the Tang, Volume 825 [Z], Beijing: Zhonghua Book Company, 1983, p8697-8698.

[14] (Qing Dynasty) Written by Dong Gao, etc. Complete Prose Works of the Tang, Volume 826 [Z], Beijing: Zhonghua Book Company, 1983, p 8708.

[15] Edited by Fu Xuancong, Collation and Annotation of Biography of Gifted Scholars of Tang Dynasty [M], Beijing: Zhonghua Book Company, 1995, p1.

[16] (Song Dynasty) Written by Ou Yangxiu, Song Qi. New Book of Tang [M], Beijing: Zhonghua Book Company, 1975, p2776.

[17] (Song Dynasty) Written by Chen Zhensun. Catalogic Book Zhizhai Shulu Jieti [M], Shanghai: Shanghai Chinese Classics Publishing House, 1987, p579.

[18] Edited by Fu Xuancong, Collation and Annotation of Biography of Gifted Scholars of Tang Dynasty [M], Beijing: Zhonghua Book Company, 1995, p1.

[19] Ming Dynasty, Wang Liangchen. Mysterious True Essence of Comments on Poems [M], Book Series Not Collected in Siku Quanshu [Z], Beijing: Beijing Publishing House, 2000, p768.

[20] (Qing Dynasty) Written by Dong Gao, etc. Complete Prose Works of the Tang, Volume 825 [Z], Beijing: Zhonghua Book Company, 1983, p8697.

[21] Edited by Fu Xuancong, Collation and Annotation of Biography of Gifted Scholars of Tang Dynasty [M], Beijing: Zhonghua Book Company, 1995, p1. 